\title{
Emergent constraints on climate-carbon cycle feedbacks from tropical atmospheric aridity
}

\author{
Armineh Barkhordarian ( $\sim$ Armineh.barkhordarian@uni-hamburg.de ) \\ Institute of Oceanography, University of Hamburg \\ Kevin Bowman \\ Jet Propulsion Laboratory \\ Noel Cressie \\ University of Wollongong \\ Jeffrey Jewell \\ Jet Propulsion Laboratory \\ Junjie Liu \\ California Institute of Technology
}

\section{Article}

Keywords: carbon cycle, climate change, tropical climate, carbon balance

Posted Date: January 12th, 2021

DOI: https://doi.org/10.21203/rs.3.rs-132691/v1

License: (c) (1) This work is licensed under a Creative Commons Attribution 4.0 International License. Read Full License 


\title{
Emergent constraints on climate carbon cycle feedbacks from tropical atmospheric aridity
}

\author{
Armineh Barkhordarian ${ }^{1,2}$, Kevin W. Bowman ${ }^{2,3}$, Noel Cressie ${ }^{4}$, Jeffrey Jewell ${ }^{3}$, \\ and Junjie Liu ${ }^{3}$ \\ ${ }^{1}$ Institute of Oceanography, Universität Hamburg, Hamburg, Germany \\ ${ }^{2}$ UCLA Joint Institute for Regional Earth System Science and Engineering (JIFRESSE), CA, USA \\ ${ }^{3}$ Jet Propulsion Laboratory, California Institute of Technology, Pasadena, CA, USA \\ ${ }^{4}$ University of Wollongong, Wollongong, Australia
}

December 20, 2020

\begin{abstract}
The vulnerability of the terrestrial tropical carbon cycle to changes in climate, especially temperature and moisture, remains one of the largest sources of uncertainty in future climate projections. Harnessing new satellite-driven global carbon reanalysis, we show here that tropical atmospheric aridity, which is directly related to the atmospheric vapor pressure deficit (VPD), is a causal driver of the interannual variability of the tropical net carbon balance and consequently the $\mathrm{CO}_{2}$ growth rate with observed present-day sensitivities of $-3.2 \pm 0.62 \mathrm{GtC}$ $\mathrm{mb}^{-1} \mathrm{yr}^{-1}$. Our results provide evidence that a large part of tropical net biome exchange variability is indirectly driven by land-atmospheric coupling via VPD variations that can not be explained by tropical temperatures alone. Furthermore, we find that there is an emergent relationship between the sensitivity of the tropical carbon balance to VPD and the long-term response of tropical-land carbon storage to increase in VPD across an ensemble of Earth
\end{abstract}


System Models used in the Climate Model Intercomparison Project 6 (CMIP6). Employing a hierarchical emergent constraint, the global carbon — climate feedback from aridity is $-22 \pm$ $11 \mathrm{GtC} \mathrm{mb}^{-1}$, which represents a substantial reduction in uncertainty relative to the CMIP6 ensemble. Our findings show that atmospheric aridity is an important proxy for the combined effects of both water and temperature on the terrestrial carbon balance and a key predictor of carbon-climate feedbacks.

\section{Introduction}

One of the largest sources of uncertainty in predicting the climate response to fossil fuel emissions are carbon - climate feedbacks, which modulate the relationship between $\mathrm{CO}_{2}$ emissions and concentrations. This relationship is evident in the year-to-year fluctuations in the atmospheric carbon dioxide $\left(\mathrm{CO}_{2}\right)$ growth rate (CGR), which are primarily due to the variations in land ecosystem's carbon uptake (Ahlström et al., 2015). Land ecosystems have acted as a substantial sink for atmospheric $\mathrm{CO}_{2}$, accounting for about $30 \%$ of anthropogenic $\mathrm{CO}_{2}$ emissions (Friedlingstein et al., 2019). The short-term sensitivity of CGR fluctuations to tropical temperature variability has been well documented (Wang et al., 2013; Cox et al., 2013; Wang et al., 2014; Fang et al., 2017), but identifying the role of water stress (Jung et al., 2017) at the ecosystem scale on carbon cycle is still elusive (Zscheischler et al., 2018).

There are a number of moisture processes that control carbon fluxes. Stocker et al. (2019) argued that soil moisture impacts light use efficiency leading to larger interannual variability in gross primary productivity (GPP) over a larger number of biomes than previously expected. Terrestrial water storage, like tropical temperatures, is also well-correlated with CGR (Humphrey et al., 2018) and affects long-term carbon storage (Green et al., 2019). The covariation of these processes can lead to compound affects that are stronger than any isolate, single process (Zhou et al., 2019b) that reflects in part the complexity from land-atmosphere feedbacks (Zhou et al., 2019a). While Earth System Models (ESM) represent many of these processes, capturing the 
balance of these processes is challenging leading to a wide range of carbon-climate feedbacks. Consequently, there is a critical need for a framework to adjudicate this balance with observational constraints. A promising observational constraint is atmospheric aridity, which is at the nexus of atmospheric-water-carbon coupling.

For example, forests are physiologically dependent on atmospheric demand for ecosystem water, which is driven by two factors: vapor pressure deficit (VPD; saturation minus actual water vapor pressure) and net radiation (Bonan, 2019). High VPD limits surface conductance and evapotranspiration to a greater extent than soil moisture in many biomes (Novick et al., 2016), particularly in mesic forest ecosystems that drive the terrestrial carbon sink (Pan et al., 2011). Recent results argue that VPD exerts a more direct regulation on plant stomatal conductance and hence ecosystem productivity loss than temperature (Zhou et al., 2019b). The study by Konings et al. (2017) highlighted that increases in VPD rather than changes in precipitation substantially influenced vegetation productivity.

In the tropics, observational records indicate that VPD is increasing over the rainforests of the Amazon Basin with values well beyond the range of trends attributable to natural variability of the climate system (Barkhordarian et al., 2019). Increasing VPD is observed to be associated with more incoming solar radiation, which naturally increase the demand for photosynthesis and transpiration. However, with recent trends in the observed soil water deficit from reduced dryseason precipitation (Barkhordarian et al., 2018), the risk of mortality from physiological and hydraulic failure substantially increases (Anderegg et al., 2015) with the potential to upset the tropical carbon balance (Sulman et al., 2016). Persistent changes in atmospheric aridity and seasonal moisture availability could fundamentally change Amazon forest function that may augur a "tipping point" (Lenton et al., 2008).

VPD is often overlooked in carbon cycle research despite its critical role in terrestrial water use and carbon uptake (Novick et al., 2016). In contrast, in this study we show that atmospheric demand for ecosystem water, which is directly related to the atmospheric vapor pressure deficit, is an important control on the variability of the tropical carbon balance and consequently the $\mathrm{CO}_{2}$ 
growth rate (CGR). In order to distinguish between causal and correlative linkages between VPD and CGR, we apply the convergent cross-mapping technique (Sugihara et al., 2012), which is a causal detection technique. These results in conjunction with partial correlation analysis point to a dependence of atmospheric $\mathrm{CO}_{2}$ on enhanced atmospheric aridity beyond what would be expected from temperature alone.

Satellite-based carbon reanalysis systems such as the NASA Carbon Monitoring System Flux (CMS-Flux) provide critical new information on the tropical carbon balance and its relationship to the global carbon cycle (Liu et al., 2014b). CMS-Flux data show that the CGR can be largely explained by tropical net biome exchange (NBE) interannual variability, which in turn is driven by atmospheric aridity. We furthermore show that this dependency is present in Earth System Models (ESMs) participating in the C4MIP (Jones et al., 2016) contribution to the sixth phase of CMIP (CMIP6; (Eyring et al., 2016)). Moreover, ESMs show a correlation between short-term sensitivity of tropical NBE to tropical VPD and long-term response of land-carbon storage to tropical VPD. We leverage this relationship with CMS-Flux NBE sensitivities to aridity in the hierarchical emergent constraint (HEC) framework (Bowman et al., 2018) to narrow the range of self-consistent carbon-climate feedbacks. The HEC framework formally accounts for the relationship between future climate, current climate, and observations through conditional-probability distributions.

\section{Results}

\subsection{Sensitivity of global CGR and tropical NBE to tropical atmo- spheric aridity}

We first assess the short-term (interannual) sensitivity of global $\mathrm{CO}_{2}$ growth-rate (CGR) to VPD $\left(\gamma_{V P D}^{C G R}\right)$ over the tropical land area $\left(23^{\circ} \mathrm{N}-23^{\circ} \mathrm{S}\right)$ by regressing $\mathrm{CGR}$ interannual variability (IAV) from the Global Carbon Project (GCP, Friedlingstein et al. (2019)) with the observed VPD IAV 
(for simplicity CGR is converted to equivalent GtC/yr). The gradient of the ordinary least squares linear regression between de-trended anomalies in the CGR and the tropical VPD defines $\gamma_{V P D}^{C G R}=$ $d C G R / d V P D$. We calculate VPD from two independently-developed datasets: (1) VPD from ERA5 reanalysis temperature and dew point (Hersbach et al., 2020) and (2) VPD from stationbased records of water vapor pressure and temperature from CRUv4 (Climatic Research Unit) (Harris et al., 2020).

Figure 1 reveals a tight covariation between CGR and VPD over the last 30 years (1989-2018) with correlations on the order of $+0.76(P=0.000)$ and $+0.70(P=0.000)$ for ERA5 and CRUv4, respectively. Positive correlations indicate that years characterized by an anomalously high VPD are associated with also high CGR, which suggest a weakening of the land carbon uptake.

We calculated how $\gamma_{V P D}^{C G R}$ changes with time using a 30-yr moving window between 1960 and 2018 (Fig 1b) (both variables detrended). We exclude data for 2 years following large volcanic eruptions (Mount Agung, 1963; El Chichon, 1982; and Mount Pinatubo, 1991). Within each 30-yr moving window, there is a significant positive correlation between CGR and VPD in the range of $[0.52-0.71](\mathrm{P} \leq 0.01)$. Furthermore, $\gamma_{V P D}^{C G R}$ increased by a factor of 1.6 , from $1.40 \pm 0.58$ $\mathrm{GtC} / \mathrm{yr} / \mathrm{mb}$ to $2.28 \pm 0.42 \mathrm{GtC} / \mathrm{yr} / \mathrm{mb}$ between 1960-1995 and 1989-2018 (Fig 1b). These results are broadly consistent with increases of carbon cycle sensitivity to tropical temperature variations (Wang et al., 2014).

The time series of observed VPD anomalies (relative to the mean of 1900-2018 calculated from station-based CRUv4 dataset) and its components (actual and saturated vapor pressure) over tropical vegetated areas indicate that the atmospheric demand for water has been increasing since the 1990's (Fig 1d), suggesting that the surface atmospheric layer is drying out. Thus, the increasing tendency in $\gamma_{V P D}^{C G R}$, may point to an increasing amplitude of positive feedbacks in the 21st century.

We would expect that tropical VPD anomalies directly impact the tropical terrestrial carbon balance that would in turn modulate CGR. To evaluate this hypothesis, we exploit the recentlyreleased Net Biosphere Exchange (NBE) dataset from the NASA Carbon Monitoring System Flux 
(CMS-Flux; Liu et al. (2020)). CMS-Flux is a carbon cycle data assimilation system that incorporates global satellite-driven measurements across the carbon cycle to attribute $\mathrm{CO}_{2}$ variability to spatially-resolved processes (Liu et al., 2014a, 2017; Bowman et al., 2017). The correlation between global CGR and Tropical NBE over 2010-2018 is -0.92 $(P=0.000)$ (Extended data Fig 1$)$ confirming that CGR variability is dominated by tropical NBE implicating the tropics as the driver of CGR variability(Piao et al., 2020). The regression between NBE and CGR leads to an annual sensitivity of $\gamma_{N B E}^{C G R}=-0.78 \pm 0.12$. In other words, on average for 1 gram less tropical land carbon uptake (NBE), there is 0.78 additional gram of carbon in the atmosphere. The results that $\gamma_{N B E}^{C G R}<1$ suggests that there is a partial terrestrial extratropical or oceanic offset in uptake.

Consequently, we focus on the tropics in Fig 2 a that shows yearly de-trended anomalies of NBE versus VPD and their associated uncertainties. In the absence of formal uncertainties provided by the data products, we associate the standard deviation of the uncertainty in VPD as simply the difference between the two observed datasets (CRUv4 and ERA5). The NBE uncertainties provided by the data product are calculated from a Monte Carlo method as part of the assimilation process (Liu et al., 2014a).

Observations of tropical NBE anomalies over the 2010-2018 period show a high negative correlation of $-0.87(P=0.00)$ with VPD anomalies (calculated as the mean of the two observed VPD records) as shown in Fig 2a. We also note that the correlation is higher than the observed coupling between NBE and near surface $(2 \mathrm{~m})$ temperature $(r=-0.78)$. For each VPD time series, the correlation is $-0.86(P=0.00)$ and $-0.80(P=0.00)$ with ERA5 and CRUv4, respectively. The high correlation between VPD and NBE indicates that high atmospheric demand for water weakens the terrestrial carbon sink. Based upon the previous regression, we quantify the observed yearly sensitivity to be $\gamma_{V P D}^{N B E}=-3.2 \pm 0.62 \mathrm{GtC} / \mathrm{yr} / \mathrm{mb}$ (Fig 2a). In other words, for $1 \mathrm{mb}$ increase in water vapor pressure deficit, there is 3.2 grams less carbon uptake. 


\subsection{Detecting causal relationships between VPD and CGR}

While Figs 1 and 2a show a strong correlation between VPD and NBE-and by extension CGR-the question remains whether that relationship is causal or spurious, perhaps a mutual dependence on a third variable, e.g., temperature. Confounding variables are endemic of complex Earth System processes (Nes et al., 2015). However, new techniques based upon causality analysis are powerful tools to understand the relationship between variables in complex systems. The convergent crossmapping (CCM) technique introduced in Sugihara et al. (2012) exploits Takens' theorem (Takens, 1981), which shows that the essential information of a multidimensional dynamical system is retained in the times series of any single variable of that system. Consequently, if variable $\mathrm{X}$ influences an observed variable $\mathrm{Y}$, then variable $\mathrm{X}$ can be reliably predicted from the time-series history of variable Y (generalized Takens' theorem; Deyle and Sugihara, 2011). Consequently, we employ the CCM technique to measure the extent to which the historical record of $\mathrm{CO}_{2}$ growth rate reliably predicts tropical VPD time series. This prediction skill is quantified by calculating the correlation coefficient between predicted (CGR-reconstructed VPD) and observed values of VPD.

We limit the analysis to CGR as the tropical NBE record is too short, but we have shown that CGR is indicative of tropical net carbon anomalies (Extended Data Fig. 1). In Fig 1c, the prediction skill $\left(\rho_{C C M}\right)$ is defined as the correlation coefficient between predictions (CGRreconstructed VPD) and observations (VPD), and the length of timeseries refers to the number of observation years (1960-2019, excluding volcanoes). Prior to the analysis "predictability" of VPD timeseries is tested and the optimal embedding dimension (E) equal to 4 is chosen (See Methods). Causality is established in CCM when 1) the prediction skill $\left(\rho_{C C M}\right)$ is statistically different from zero when using the full time series and 2) when the prediction skill demonstrates convergence, i.e., $\rho_{C C M}$ increases as more of the time series is included to reconstruct the VPD. The CCM results (Fig 1c) indicates that the CGR-reconstructed VPD curve (the prediction skill) gradually converges to a statistically significant values $\left(\rho_{C C M}=0.73, P=0.00\right)$ as time-series 
length increases. Since convergence is a key property that distinguishes causation from simple correlation we conclude that CGR variations are causally linked to VPD variations.

\subsection{Confounding effects of VPD and temperature on correlation with NBE.}

VPD is a function of both temperature and relative humidity. In order to assess the confounding influence of temperature, we calculated a partial correlation between CMS-Flux tropical NBE and VPD while controlling for the effect of $2 \mathrm{~m}$ temperature. We note that NBE-VPD correlation $(r=-0.87)$ is higher than NBE-Temp correlation $(r=-0.78)$. For CMS-Flux tropical NBE and VPD, the partial correlation is $r=-0.70, P=0.04$, (gray bar in Fig 2b). The relatively minor reduction (0.17) between the regular and partial correlation indicates that NBE variability related to VPD is not attributable to temperature alone. However, the reverse is not true: the partial correlation between NBE and temperature is $r=-0.30(P=0.79$, Fig 2c), when accounting for the confounding effects of VPD. We further use the SMOS-MIRAS satellite soil moisture dataset (Al Bitar et al., 2017) and show that the tropical NBE has a tight covariation with soil moisture $(r=+0.83, P=0.00)$ over the overlapping 2010-2018 period (green bar in Fig 2b).

Too see whether this relationship is also captured in models, we analyzed 12 Earth System Models (ESMs) from the C4MIP (Jones et al., 2016) contribution to the sixth phase of CMIP (CMIP6; Eyring et al. (2016)). The name of the models are given in Extended data Table 1. The correlations between tropical NBE and tropical VPD with 12 ESMs span $[-0.75--0.92](P=0.000$; Extended data Table 1) while the partial correlations are in the range of [-0.20 - -0.62]. Of these, 10 out of 12 ESMs have statistically significant partial correlations. While the correlation between NBE and VPD is high across over all ESMs, the diversity of partial correlations point to a range of approaches to relate VPD to temperature and moisture processes. This suggests that some models with low partial correlations have processes that decouple moisture and temperature, e.g, soil moisture parameterizations. Similar to what we found for the observations, application of the 
convergent cross-mapping (CCM) causality technique to the ESMs also show a causal relationship between the VPD and NBE variations in ESMs (Extended data Fig 3). Consequently, the climate model simulations by and large represent the causal relationship between tropical NBE and VPD and its dependence on both temperature and moisture processes.

In addition to a partial correlation analysis, we can also look at the surface energy partitioning. The partitioning of available energy at the land surface into sensible $\left(\mathrm{Q}_{s}\right)$ and latent heat $\left(\mathrm{Q}_{l}\right)$ informs on the coupling strength between land and atmosphere. The Bowen ratio $\left(\mathrm{Q}_{s} / \mathrm{Q}_{l}\right)$ translates variations in the state of the land surface (e.g. soil moisture) into changes in the state of the atmosphere (e.g. atmospheric aridity) (Teuling et al., 2017). The Bowen ratio was calculated from ERA5 reanalysis with high-quality surface turbulent fluxes (Martens et al., 2020). The percent variance of VPD variability explained by Bowen ratio is calculated by regressing the normalized (i.e., mean removed and divided by the standard deviation) VPD time series against the Bowen ratio over the 1981-2019 time period. Results (Fig 2d) suggest that over the tropical land, VPD is primarily controlled by land-atmospheric interactions. Most notably over the southeast Amazon and Congo basin where more than 80\% of VPD variations over 1981-2019 time period can be explained by a lack of surface moisture (energy partitioning favoring less evapotranspiration) that is the case when $\mathrm{Q}_{s}$ increases at the expense of $\mathrm{Q}_{l}$ leading to less evaporative cooling. The significant positive partial correlation between Bowen ratio and VPD after controlling for the effect of temperature, $r=+0.56$ (Fig 2e), further demonstrates that most of the information on Bowen ratio variations that is contained in VPD cannot be found in temperature. In addition, VPD shows a significant decoupling with soil moisture on overlapping 2010-2018 period, $r=-0.83$ (Extended data Fig 4). These results solidify the conclusion that that tropical VPD is substantially impacted by surface moisture processes through land-atmospheric coupling.

Results here provide substantial observational and model evidence that the tropical terrestrial NBE is coupled to changes in atmospheric aridity independent from the tropical temperature variations. Furthermore, these results imply that more carbon will be lost from tropical land if atmospheric aridity continues to rise (Yuan et al., 2019; Barkhordarian et al., 2019) from the 
compound effects of warming and drying. Consequently, linkages between carbon and water cycles are crucial to understanding the interannual variability of global net carbon exchange and what it may portend for carbon-climate feedbacks. The question is, then, what this finding tells us about future carbon response.

\subsection{Atmospheric aridity - carbon cycle Feedback in CMIP6 Models}

We quantify atmospheric aridity - carbon cycle feedback parameters $\left(\gamma_{T L}\right)$ across an ensemble of ESMs using the 1pctCO2 simulation, which is a standard idealized experiment forced with a $1 \% / \mathrm{yr}$ increase of atmospheric $\mathrm{CO}_{2}$ concentration up to $4 \times \mathrm{CO}_{2}$, starting from the preindustrial value for 1850 of $~ 285$ ppmv. We follow previous studies (Friedlingstein et al., 2003; Gregory et al., 2009; Arora et al., 2020) in writing the future change in tropical land carbon storage, $\Delta C_{T L}$ as

$$
\Delta C_{T L}=\gamma_{T L} \Delta V P D_{T L}+\beta_{T L} \Delta C_{a}
$$

where subscript "TL" represents "Tropical Land", $\gamma_{T L}$ and $\beta_{T L}$ are the carbon-climate and carbon-concentration feedback parameters, respectively. In contrast to previous studies, we use changes in tropical mean VPD (atmospheric aridity), $\triangle V P D_{T L}$, as a proxy for carbon-climate feedbacks. This approach is also slightly different from earlier work in that the feedbacks are confined to sensitivities of tropical land carbon storage to climate change and direct $\mathrm{CO}_{2}$ effects (Friedlingstein et al., 2003, 2006). Extratropical terrestrial carbon feedbacks are not considered here. We estimate $\gamma_{T L}$ parameters from 12 ESMs (Extended data Table 2). Two configurations of ESMs are used: biogeochemically-coupled and fully-coupled simulations (Arora et al., 2020). In biogeochemically-coupled simulations (hereafter $\mathrm{BGC}$ ) the radiative effects of $\mathrm{CO}_{2}$ are fixed to control preindustrial $\mathrm{CO}_{2}$ concentrations whereas the carbon cycle is exposed to a $1 \% / \mathrm{yr}$ increase in atmospheric $\mathrm{CO}_{2}$. Consequently, vegetation can respond physiologically to increases in $\mathrm{CO}_{2}$ without the concomitant changes in climate. In fully coupled simulations (hereafter COU) both the biogeochemical and the radiative processes respond to increasing $\mathrm{CO}_{2}$. 
The combination of COU and BGC simulations are used to isolate the the direct effects of $\mathrm{CO}_{2}$ on land carbon sinks (i.e., effect of $\mathrm{CO}_{2}$ on photosynthesise and water-use-efficiency) from the effects of climate change (i.e., radiative effect of $\mathrm{CO}_{2}$ ). The $\mathrm{CO}_{2}$ concentration is prescribed to be identical in both COU and BGC runs. Consequently, the carbon-concentration feedback, $\Delta C_{a}$, is the same in both simulations $\left(\Delta C_{a^{C O U}}=\Delta C_{a^{B G C}}\right)$. With this configuration, equation 1 yields an expression for the atmospheric aridity-carbon cycle feedback parameter $\left(\gamma_{T L}\right)$ :

$$
\gamma_{T L}=\frac{\Delta C_{T L}^{C O U}-\Delta C_{T L}^{B G C}}{\Delta V P D_{T L}^{C O U}-\Delta V P D_{T L}^{B G C}}
$$

The changes are computed for the tropical band $\left(23^{\circ} \mathrm{N}\right.$ and $\left.23^{\circ} \mathrm{S}\right)$ as the difference between year 90 and year 110 after the start of the simulation at $1850 \mathrm{CO}_{2}$ concentration levels (Wenzel et al., 2014).

The VPD change in the BGC simulation (Fig. 3a, green line) is about $15 \%$ of changes in COU (Fig. 3a, blue line). The small VPD changes in BGC are due to factors including 1) reduction in transpiration and hence evaporative (or latent heat) flux associated with stomatal closure (Ainsworth and Long, 2005; Cao et al., 2010), 2) increase in vegetation leaf area index, which decreases land surface albedo and hence increases absorbed solar radiation (Arora et al., 2020; Ainsworth and Long, 2005). There are higher cumulative values of atmosphere-land $\mathrm{CO}_{2}$ flux uptake in the BGC simulation (Fig. 3b, blue line) compared to the COU simulation (Fig. 3b, green line), indicating that the overall impact of the $\mathrm{CO}_{2}$ greenhouse gas effect is to weaken the land carbon storage (Arora et al., 2020).

Using the difference of COU and BGC simulations in equation 2, atmospheric aridity - carbon cycle feedback parameter $\left(\gamma_{T L}\right)$ is quantied in terms of carbon loss per unit atmospheric aridity increase $(\mathrm{GtC} / \mathrm{mb})$ as shown for each model in Extended data Table 2. All models show a negative $\gamma_{L T}$, meaning that long-term increases in atmospheric aridity will compromise the carbon cycle's sequestration capacity. However, the results range from -1.6 GtC/mb in MPI-ESM1.2-LR to -68.5 $\mathrm{GtC} / \mathrm{mb}$ in GFDL-ESM4. 
By focusing specifically on tropical land are $\left(23^{\circ} \mathrm{N}-23^{\circ} \mathrm{S}\right)$ from CMS-Flux, we can directly estimate $\gamma_{V P D}^{N B E}=d N B E / d V P D$, exploiting the relationship that the interannual variability in $\mathrm{CO}_{2}$ growth rate is dominated by the interannual variability of the tropical NBE (Extended data Figure 1). In order to calculate the $\operatorname{ESM} \gamma_{V P D}^{N B E}$ the annual mean tropical land $\mathrm{CO}_{2}$ fluxes and VPD are regressed using a detrended 11 year running mean. The resulting model $\gamma_{V P D}^{N B}$ has an impressive range of sensitivities (Extended data Table 2) from -1.1 $\pm 0.24 \mathrm{GtC} \mathrm{mb}^{-1} \mathrm{yr}^{-1}$ for NCAR-CESM2 up to -11.4 GtC $\mathrm{mb}^{-1} \mathrm{yr}^{-1}$ for GFDL-ESM4. However, the sensitivities in 9 out of

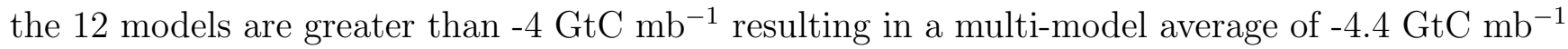
$\mathrm{yr}^{-1}$.

Models that respond strongly to internnual variations in VPD also tend to have a weaker longterm carbon uptake to increases in long-term VPD. This relationship is shown in Fig 4a, which shows a linear regression between $\gamma_{V P D}^{N B E}$ versus $\gamma_{T L}$ with a Pearson correlation, $r=0.90$. It is this relationship that serves as a basis for an "emergent constraint" between interannual variations in NBE with VPD and the long-term response of land carbon storage to atmospheric aridity.

\subsection{Constraining aridity — carbon cycle feedback in ESMs projection}

A Hierarchical Emergent Constraint (HEC) is employed to calculate an observationally-constrained range of atmospheric aridity - carbon cycle feedback parameters $\left(\gamma_{T L}\right)$. Following Bowman et al. (2018), the HEC framework aims to generalize previous classic EC studies (e.g., Hall and Qu, 2006; Cox et al., 2013; Hall et al., 2019) by explicitly relating future climate $\left(\mathrm{z}_{t+\tau}\right)$, current climate $\left(\mathrm{x}_{t}\right)$ and the observations $\left(\mathrm{y}_{t}\right)$ through conditional-probability distributions (see Methods). Applying the HEC framework to atmospheric aridity - carbon cycle feedback parameters computed previously, we map current climate, $x_{t} \rightarrow \gamma_{V P D}^{N B E}$, and future climate, $z_{t+\tau} \rightarrow \gamma_{T L}$, which is the impact of atmospheric aridity on the long-term tropical land carbon storage. The observational constraint, $y_{t} \rightarrow \hat{\gamma}_{V P D}^{N B E}$, is calculated from the sensitivity of NBE from CMS-Flux to atmospheric aridity $\left(\hat{\gamma}_{V P D}^{N B E}\right.$, where $\hat{\gamma}$ denotes an estimate of $\gamma$, Fig 2a). The observed short-term sensitivity, $y_{t}$ $=-3.2 \mathrm{GtC} / \mathrm{yr} / \mathrm{mb}$ with an observational uncertainty of $\sigma_{n_{t}}=0.62 \mathrm{GtC} / \mathrm{yr} / \mathrm{mb}$. 
The HEC of the carbon - climate feedback, $\left[z_{t+\tau} \mid y_{t}\right]$, is shown in Fig $4 \mathrm{~b}$ (computed from equation (3) in Methods). The first moment (computed from equation (4) in Methods), is $\mu_{z_{t+\tau} \mid y_{t}}=$ $-22.2 \mathrm{GtC} / \mathrm{mb}$, and the square root of its second moment (computed from equation (5) in Methods) is $\sigma_{z_{t+\tau} \mid y_{t}}=11.4 \mathrm{GtC} / \mathrm{mb}$. The conditional mean is smaller than the mean of the CMIP6 ensemble, $\mu_{z_{t+\tau}}=-28.4 \mathrm{GtC} / \mathrm{mb}$, and the conditional uncertainty, $\sigma_{z_{t+\tau} \mid y_{t}}$, is about 1.9 times less than CMIP6 ensemble spread, $\sigma_{z_{t+\tau}}=21.1 \mathrm{GtC} / \mathrm{mb}$.

The larger uncertainty in the CMIP6 ensemble makes the null hypothesis (i.e., VPD has no substantial impact on carbon storage) to be far more likely than the HEC constraint. For the projected VPD increase of $8.6 \mathrm{mb}$ (Fig. 3), the tropical carbon storage would decrease by $189.2 \pm$ 89.04 GtC.

\section{Conclusions}

Findings in this study offer a new perspective on the under-appreciated role of atmospheric aridity on the carbon balance and the fate of future land carbon uptake. There is observational and model evidence that tropical VPD is one of the causal drivers of the $\mathrm{CO}_{2}$ growth rate fluctuations. The combination of causality analysis and partial correlations point to mechanistic moisture drivers of atmospheric CGR variations independent of temperature. A large part of the tropical NBE variations, and consequently the CGR, are indirectly driven by surface moisture processes via VPD. The observed short-term sensitivity, $\left(\hat{\gamma}_{V P D}^{N B E}=-3.2 \pm 0.6 \mathrm{GtC} / \mathrm{yr} / \mathrm{mb}\right)$ and our HEC analysis reduces the estimate of $\gamma_{L T}=-28.4 \mathrm{GtC} / \mathrm{mb}$ for CMIP6 models to $\hat{\gamma}_{L T}=-22.2 \mathrm{GtC} / \mathrm{mb}$ for the HEC with about a factor of 2 reduction in uncertainty relative to CMIP6 models alone.

While ESMs broadly represent NBE dependencies on VPD, these analysis reveal substantial differences between models. In most cases their partial correlation analysis is substantially lower than observed, often by 0.5 or more. This suggests that more complex carbon-water interactions are not getting captured-and that temperature is a more dominant role than is warranted in the data. However, process deficiency also leads to caution in the interpretation of the HEC. If 
models across the ensemble are not capturing these processes, then we might expect the accuracy of the HEC to be compromised. Observations play a critical role in falsifying theories (Popper, 2005; Tarantola, 2006). The HEC constraint says less about the models that agree well with the observations and more about models that do not. Long-term projections from these models should be treated with caution because the HEC shows inconsistency with these observations is directly linked to the logical consistency of those projections. Consequently, while this analysis can not definitively reject the possibility that the feedback from atmospheric aridity could in the future, in fact, be high, (e.g., -70 GtC/mb), the $\mathrm{HEC}$ can reject the specific mechanisms and parameters implemented in those models inconsistent with observations. In other words, the projections could coincidentially be right, but not for the right reasons.

While clearly VPD is an important contributor, the balance of moisture processes including soil moisture and evapotranspiration, and their interactions on VPD has not been studied extensively here. Rather, VPD is treated as a proxy of broader land-atmosphere interactions. VPD is more directly related to GPP, but the response here in NBE could also be related to covarying moisture processes. The causality and statistical analysis described here could further elucidate the roles of those processes. Moreover, the extension of this approach to a multivariate case, e.g., GPP and NBE to multiple moisture processes, is a subject of future research. The HEC formulation considered a pan-tropical analysis, but as shown in Liu et al. (2017), regional responses to forcing such as VPD are likely not the same. The application of HEC to a more spatially-explicit response is a subject of future research.

The potential future extensions of this analysis are compelling given that the dramatic and inexorable increases in VPD since the 1990's (Fig. 1d ; Yuan et al. (2019)) point to the persistent stress on tropical vegetation from atmospheric water demand. Consequently, there is an urgent need to improve our understanding of carbon and water coupling at multiple scales for us to better predict how long tropical forests can stand as a buffer against anthropogenic emissions and their impact on climate. 


\section{Method}

\subsection{Data}

Observation and model data used in this study are presented in Table 1 . We calculate VPD on the basis of different variables of two independently-developed datasets. From the fifth generation of ECMWF (European Centre for Medium-Range Weather Forecasts) atmospheric reanalyses (ERA5; Hersbach et al. (2020)), we use $2 \mathrm{~m}$ temperature and dew point data to calculate VPD. We further use station-based actual vapor pressure and 2m temperature from CRUv4 (Harris et al., 2020). (Eq.1 and Eq.2 in extended data). To calculate the Bowen ratio we used data from ERA5 reanalysis with high-quality surface turbulent fluxes (Martens et al., 2020). Atmospheric $\mathrm{CO}_{2}$ growth rate (CGR) is taken from the Global Carbon Project (GCP, Friedlingstein et al. (2019)). The Net Biosphere Exchange (NBE) dataset is derived from the NASA Carbon Monitoring System Flux project (CMS-Flux; Liu et al. (2020)). Soil-moisture dataset is SMOS-MIRAS L3 monthly data at $25 \mathrm{~km}$ grid resolution provided by CATDS (Al Bitar et al., 2017).

Model data (net biome productivity, temperature and relative Humidity) are derived from Earth System Models (ESMs) participating in the C4MIP (Jones et al., 2016) contribution to the sixth phase of CMIP (CMIP6; (Eyring et al., 2016)). From ESMs we use the 1pctCO2 simulation that is a standard idealized experiment forced with a 1\%/yr increase of atmospheric $\mathrm{CO}_{2}$ concentration up to $4 \times \mathrm{CO}_{2}$, starting from the preindustrial value for 1850 of $\sim 285 \mathrm{ppmv}$.

\subsection{Convergence Cross Mapping (CCM)}

In the CCM method, the first step is to determine the optimal embedding dimension (E), which describes the size of the time window used for prediction. Extended data Fig. 2b presents the variation in the prediction skill, $\rho$, as a function of E, which shows that the $\rho$ asymptotically approached a limit with the increasing E. From this analysis the embedding dimensions was set $\mathrm{E}=4$. In order to test the "predictability" of the VPD time series the S-maps method (Sugihara et al., 2012) is used. We can distinguish between red noise and nonlinear deterministic behavior 
by using S-maps as described in Sugihara et al. (2012). The S-map method suggests nonlinear dynamics in the VPD data (because of the initial increase in prediction skill for $\theta \geq 0$, followed by a gradual drop-off, Extended data Fig 2c). Therefore, the CCM method can be applied to reconstruct VPD.

\subsection{Hierarchical Emergent Constraint}

Following Bowman et al. (2018), the hierarchical emergent constraint (HEC) framework aims to generalize previous classic EC studies (e.g., Hall and Qu, 2006; Cox et al., 2013; Hall et al., 2019) by explicitly relating future climate $\left(\mathrm{z}_{t+\tau}\right)$, current climate $\left(\mathrm{x}_{t}\right)$ and the observations $\left(\mathrm{y}_{t}\right)$ through conditional-probability distributions. The conditional distributions are built on dependencies between future $\left(z_{t+\tau}\right)$ and present climate $\left(x_{t}\right)$ as well as dependencies between the present climate and observations of that climate $\left(y_{t}\right)$. The first dependency is represented by the conditional probability distribution, $\left[z_{t+\tau} \mid x_{t}\right]$ (where [.] denotes a probability density function) and the second dependency is represented by $\left[x_{t} \mid y_{t}\right]$. An HEC is calculated as

$$
\left[z_{t+\tau} \mid y_{t}\right]=\int\left[z_{t+\tau} \mid x_{t}\right]\left[x_{t} \mid y_{t}\right] d x_{t}
$$

Equation 3 can be computed analytically if the distributions are Gaussian and numerically if they are not. As discussed in Bowman et al. (2018), for the Gaussian case, an HEC can be completely described by the first and second-order moments. The first moment, i.e., the mean, of the HEC is defined as follows:

$$
E\left(z_{t+\tau} \mid y_{t}\right)=\mu_{z_{t+\tau} \mid y_{t}}=\mu_{z_{t+\tau}}+\frac{\rho \sigma_{z_{t+\tau}} \sigma_{x_{t}}}{\sigma_{x_{t}}^{2}+\sigma_{n_{t}}^{2}}\left(y_{t}-\mu_{x_{t}}\right)
$$

where $\rho$ is the correlation between $z_{t+\tau}$ and $x_{t} ; \mu_{x_{t}}$ and $\sigma_{x_{t}}^{2}$ are the mean and variance of the present climate; $\mu_{z_{t+\tau}}$ and $\sigma_{z_{t+\tau}}^{2}$ are the mean and variance of the future climate, respectively, and 

$\sigma_{n_{t}}^{2}$ is the uncertainty of the measurement $y_{t}$. The second moment of $\left[\mathrm{z}_{t+\tau} \mid \mathrm{y}_{t}\right]$ is

$$
\operatorname{var}\left(z_{t+\tau} \mid y_{t}\right)=\sigma_{z_{t+\tau} \mid y_{t}}^{2}=\left(1-\frac{\rho^{2}}{1+\left(\frac{\sigma_{x_{t}}^{2}}{\sigma_{n_{t}}^{2}}\right)^{-1}}\right) \sigma_{z_{t+\tau}}^{2}
$$

where $\sigma_{x_{t}}^{2} / \sigma_{n_{t}}^{2}$ is referred to as the signal-to-noise ratio (SNR).

As described in Bowman et al. (2018), under Gaussian assumptions, equations (4) and (5) provide a complete description of the dependence of the future climate's distribution given the observations, $\mathrm{y}_{t}$, of the current climate. We refer the interested reader to Bowman et al. (2018) for additional details. In particular, the strength of the HEC (i.e., the difference between $\left[z_{t+\tau}\right]$ and $\left.\left[z_{t+\tau} \mid y_{t}\right]\right)$ is a balance between the correlation between the future and current climate $(\rho)$ and SNR

Table 1: Observation and model data used in this study

\begin{tabular}{||c|c||}
\hline Observation data & Source \\
\hline \hline $2 \mathrm{~m}$ Temperature, Actual water vapor & Station-based CRU TS 4.4 (1901-2019 \\
\hline $2 \mathrm{~m}$ Temperature, Dew point, Surface fluxes & ERA5 reanalysis (1979-2019) \\
\hline Soil Moisture & SMOS-MIRAS Level-3 (2010-2019) \\
\hline Atmospheric $\mathrm{CO}_{2}$ Growth Rate (CGR) & Global Carbon Project (GCP) (1959-2019) \\
\hline Terrestrial Net Biosphere Exchange (NBE) & CMS Flux NBE 2020 (2010-2018) \\
\hline \hline Model data & Source \\
\hline \hline Net Biome Productivity, Temperature, Relative Humidity & 12 Earth System models from CMIP6 \\
\hline
\end{tabular}


a)

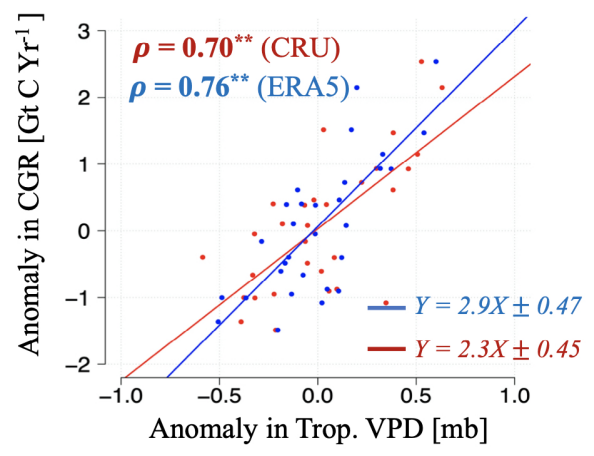

c)

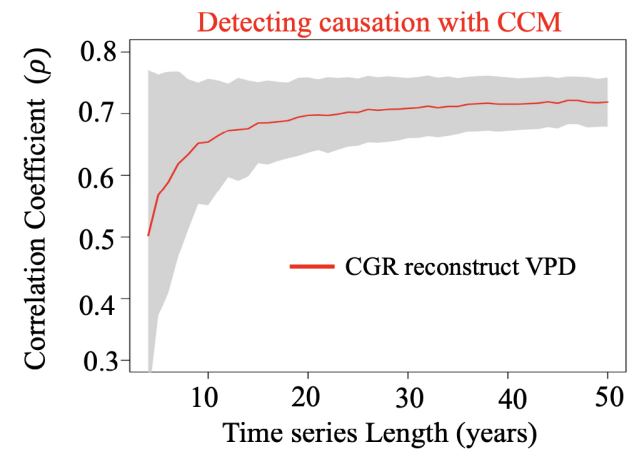

b)
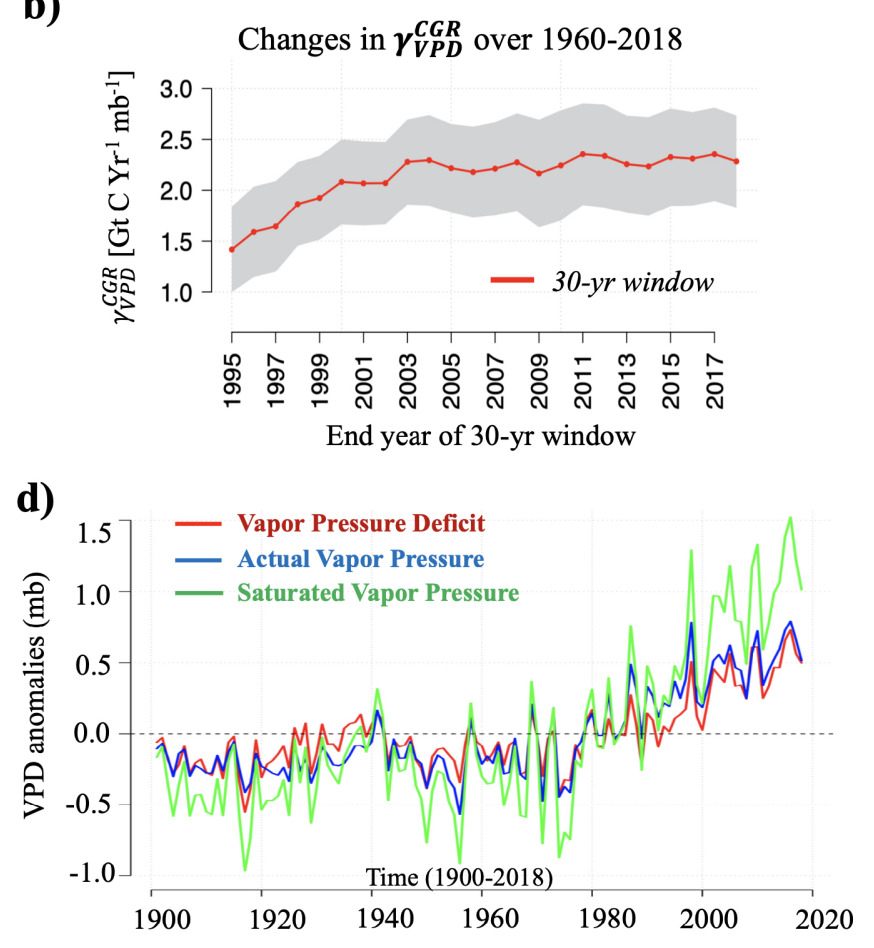

Figure 1: a) Yearly co-variation between the Global $\mathrm{CO}_{2}$ growth rate (CGR; converted from ppm to $\mathrm{GtC} / \mathrm{yr})$ and Tropical $\left(23^{\circ} \mathrm{N}-23^{\circ} \mathrm{S}\right)$ vapor pressure deficit (VPD) anomalies over the 1989-2018 period, derived from ERA5 and CRUv4 datasets. b) 30-year changes in short-term sensitivity of CGR versus VPD $\left(\gamma_{V P D}^{C G R}\right)$ over 1960-2018, units are GtC/yr/mb. Years on the horizontal axis indicate the end year of the 30-yr moving time window used to derive $\gamma_{V P D}^{C G R}$ (for example, 2015 represents period 1986-2015 in the 30-yr time window). The shaded areas show the confidence interval of $\gamma_{V P D}^{C G R}$. c) Convergent cross-mapping for reconstruction of variations in VPD from variations in CGR. Results based on 1000 bootstrapped iterations. Solid line show mean values and shaded area shows \pm 1 standard deviation. $\mathbf{d})$ Time series of observed tropical VPD anomalies (red line) over tropical vegetated area and its components; saturated (green line) and actual (blue line) water vapor pressure; derived from station-based CRUv4 dataset during 1901-2018. Unites are mb. 
a) $N B E=-3.2 * V P D \pm 0.62$

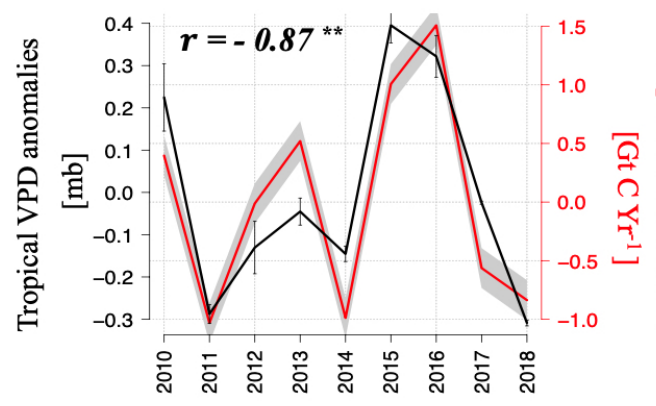

[Note: The vertical axes is inverted for NBE]

d)

Percent variance of VPD explained by Bowen ratio (1981-2018)

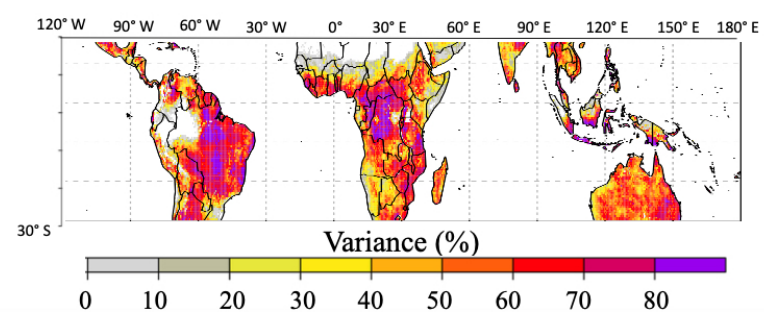

b)

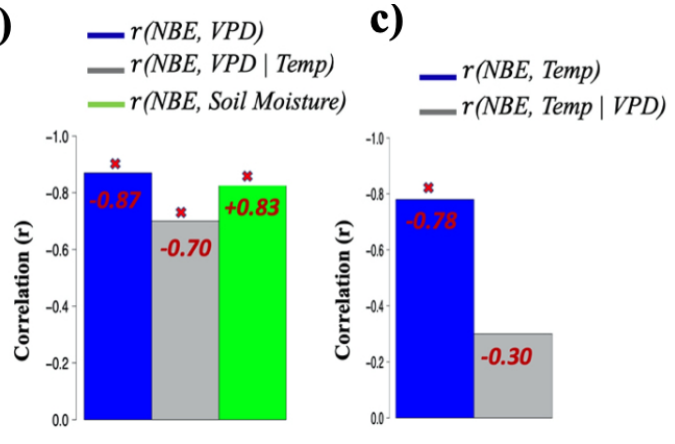

e)

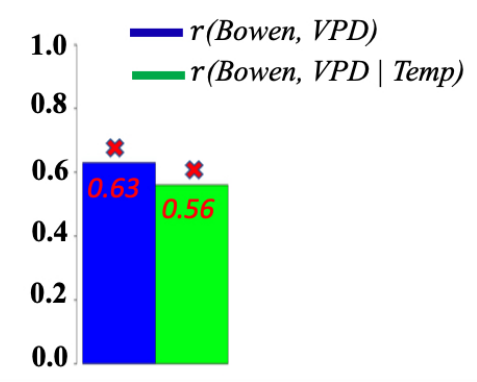

Figure 2: a) Yearly covariation between tropical anomalies of CMS-Flux net biome exchange (NBE) and atmospheric aridity (VPD) over 2010-2018. The whiskers denote the standard deviation among the two observational VPD datasets (CRUv4 and ERA5). The gray shaded area indicates the CMS-Flux NBE uncertainties. b) Correlation $(r)$ between NBE and VPD (blue bar), Partial correlation between NBE and VPD after controlling for the effect of temperature (gray bar), correlation between NBE and soil moisture (SM) (green bar, note the positive correlation between $\mathrm{NBE}$ and SM). c) Correlation between NBE and $2 \mathrm{~m}$ temperature (blue bar). Partial correlation between NBE and temperature after controlling for the effect of VPD (gray bar). Significance $(\mathrm{P}=0.00)$ is indicated with crosses. d) The percent variance of VPD variability explained by land-atmospheric interactions (Bowen ratio; proxy for energy partitioning). e) Partial correlation between Bowen ratio and VPD after controlling for the effect of temperature. 
a)

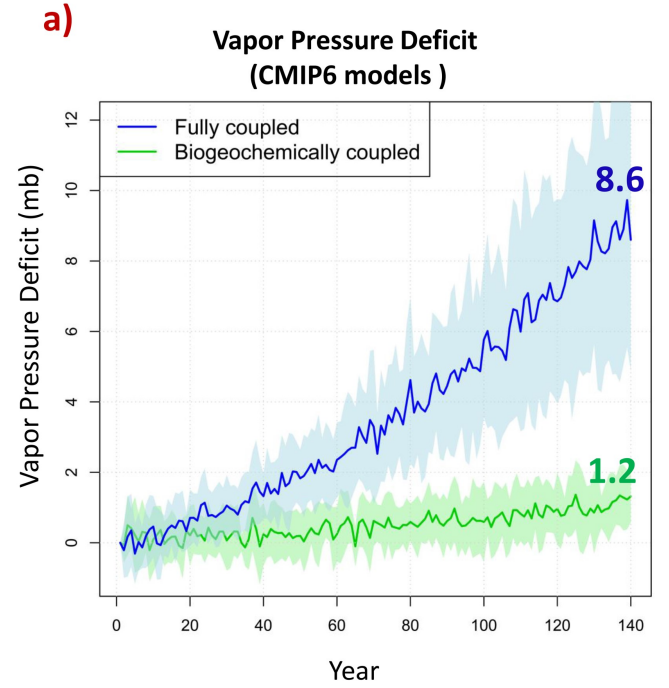

b)

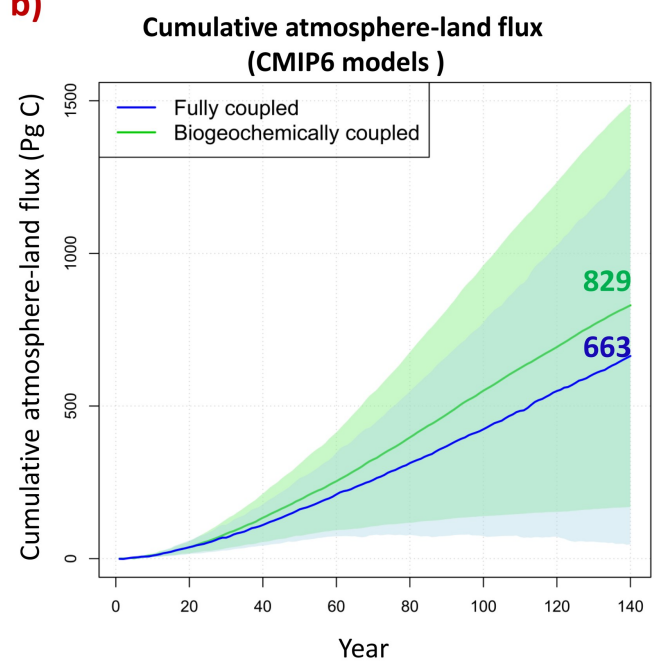

Figure 3: Quantities used to calculate atmospheric aridity-carbon cycle feedback parameters $\left(\gamma_{T L}\right)$. a) The projected tropical $\left(23^{\circ} \mathrm{N}-23^{\circ} \mathrm{S}\right)$ mean VPD change in the prescribed $\mathrm{CO}_{2}$ fully coupled (blue line) and biogeochemically coupled simulations (green line) and the range across 12 ESMs listed in Table 1. (b) Cumulative mean values and the range across 12 ESMs for annual atmosphere-land $\mathrm{CO}_{2}$ fluxes from the fully (blue line) and biogeochemicaly (green line) coupled simulations of the 1pctCO2 experiment

a)

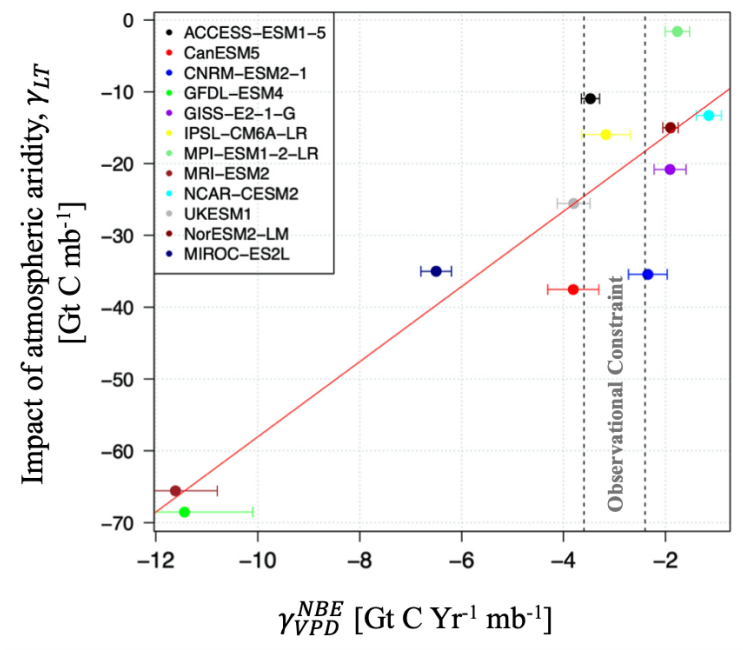

b)

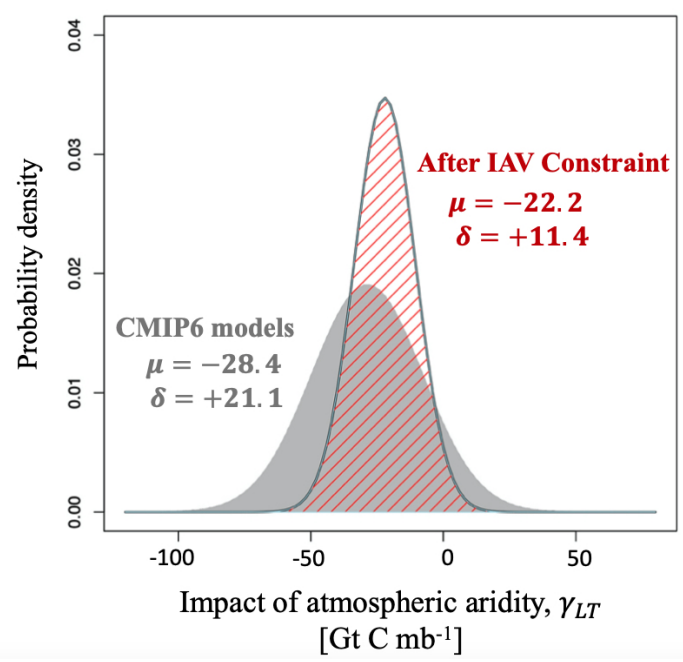

Figure 4: a) The long-term response of tropical land carbon storage to atmospheric aridity $\left(\gamma_{T L}\right)$ versus the short-term sensitivity of tropical NBE to tropical VPD $\left(\gamma_{V P D}^{N B E}\right)$ for the 12 ESMs of CMIP6. The correlation between $\gamma_{L T}$ and $\gamma_{V P D}^{N B E}$ provides an "Emergent Constraint" on the longterm response of land carbon storage to atmospheric aridity. The vertical dashed lines show the range of observed sensitivity. (b) The gray PDF is the prior PDF derived purely from the models before applying the HEC, while the red dashed PDF was derived after applying the HEC on models. 


\section{References}

Ahlström, A., Raupach, M. R., Schurgers, G., Smith, B., Arneth, A., Jung, M., Reichstein, M., Canadell, J. G., Friedlingstein, P., Jain, A. K., et al. (2015). The dominant role of semi-arid ecosystems in the trend and variability of the land co2 sink. Science, 348(6237):895-899.

Ainsworth, E. A. and Long, S. P. (2005). What have we learned from 15 years of free-air co2 enrichment (face)? a meta-analytic review of the responses of photosynthesis, canopy properties and plant production to rising co2. New phytologist, 165(2):351-372.

Al Bitar, A., Mialon, A., Kerr, Y. H., Cabot, F., Richaume, P., Jacquette, E., Quesney, A., Mahmoodi, A., Tarot, S., Parrens, M., et al. (2017). The global smos level 3 daily soil moisture and brightness temperature maps. Earth System Science Data, 9(1):293-315.

Anderegg, W. R., Flint, A., Huang, C.-y., Flint, L., Berry, J. A., Davis, F. W., Sperry, J. S., and Field, C. B. (2015). Tree mortality predicted from drought-induced vascular damage. Nature Geoscience, 8(5):367-371.

Arora, V. K., Katavouta, A., Williams, R. G., Jones, C. D., Brovkin, V., Friedlingstein, P., Schwinger, J., Bopp, L., Boucher, O., Cadule, P., et al. (2020). Carbon-concentration and carbon-climate feedbacks in cmip6 models and their comparison to cmip5 models. Biogeosciences, 17(16):4173-4222.

Barkhordarian, A., Saatchi, S. S., Behrangi, A., Loikith, P. C., and Mechoso, C. R. (2019). A recent systematic increase in vapor pressure deficit over tropical south america. Scientific reports, $9(1): 1-12$.

Barkhordarian, A., von Storch, H., Behrangi, A., Loikith, P. C., Mechoso, C. R., and Detzer, J. (2018). Simultaneous regional detection of land-use changes and elevated ghg levels: The case of spring precipitation in tropical south america. Geophysical Research Letters, 45(12):6262-6271.

Bonan, G. (2019). Climate change and terrestrial ecosystem modeling. Cambridge University Press. 
Bowman, K., Liu, J., Bloom, A., Parazoo, N., Lee, M., Jiang, Z., Menemenlis, D., Gierach, M., Collatz, G., Gurney, K., et al. (2017). Global and brazilian carbon response to el niño modoki 2011-2010. Earth and Space Science, 4(10):637-660.

Bowman, K. W., Cressie, N., Qu, X., and Hall, A. (2018). A hierarchical statistical framework for emergent constraints: Application to snow-albedo feedback. Geophysical Research Letters, $45(23): 13-050$.

Cao, L., Bala, G., Caldeira, K., Nemani, R., and Ban-Weiss, G. (2010). Importance of carbon dioxide physiological forcing to future climate change. Proceedings of the National Academy of Sciences, 107(21):9513-9518.

Cox, P. M., Pearson, D., Booth, B. B., Friedlingstein, P., Huntingford, C., Jones, C. D., and Luke, C. M. (2013). Sensitivity of tropical carbon to climate change constrained by carbon dioxide variability. Nature, 494(7437):341-344.

Deyle, E. R. and Sugihara, G. (2011). Generalized theorems for nonlinear state space reconstruction. Plos one, 6(3):e18295.

Eyring, V., Bony, S., Meehl, G. A., Senior, C. A., Stevens, B., Stouffer, R. J., and Taylor, K. E. (2016). Overview of the coupled model intercomparison project phase 6 (cmip6) experimental design and organization. Geoscientific Model Development, 9(5):1937-1958.

Fang, Y., Michalak, A. M., Schwalm, C. R., Huntzinger, D. N., Berry, J. A., Ciais, P., Piao, S., Poulter, B., Fisher, J. B., Cook, R. B., et al. (2017). Global land carbon sink response to temperature and precipitation varies with enso phase. Environmental Research Letters, 12(6):064007.

Friedlingstein, P., Cox, P., Betts, R., Bopp, L., von Bloh, W., Brovkin, V., Cadule, P., Doney, S., Eby, M., Fung, I., et al. (2006). Climate-carbon cycle feedback analysis: results from the c4mip model intercomparison. Journal of climate, 19(14):3337-3353. 
Friedlingstein, P., Dufresne, J.-L., Cox, P., and Rayner, P. (2003). How positive is the feedback between climate change and the carbon cycle? Tellus B: Chemical and Physical Meteorology, 55(2):692-700.

Friedlingstein, P., Jones, M., O'sullivan, M., Andrew, R., Hauck, J., Peters, G., Peters, W., Pongratz, J., Sitch, S., Le Quéré, C., et al. (2019). Global carbon budget 2019. Earth System Science Data, 11(4):1783-1838.

Green, J. K., Seneviratne, S. I., Berg, A. M., Findell, K. L., Hagemann, S., Lawrence, D. M., and Gentine, P. (2019). Large influence of soil moisture on long-term terrestrial carbon uptake. Nature, 565(7740):476-479.

Gregory, J. M., Jones, C., Cadule, P., and Friedlingstein, P. (2009). Quantifying carbon cycle feedbacks. Journal of Climate, 22(19):5232-5250.

Hall, A., Cox, P., Huntingford, C., and Klein, S. (2019). Progressing emergent constraints on future climate change. Nature Climate Change, 9(4):269-278.

Hall, A. and Qu, X. (2006). Using the current seasonal cycle to constrain snow albedo feedback in future climate change. Geophysical Research Letters, 33(3).

Harris, I., Osborn, T. J., Jones, P., and Lister, D. (2020). Version 4 of the cru ts monthly highresolution gridded multivariate climate dataset. Scientific data, 7(1):1-18.

Hersbach, H., Bell, B., Berrisford, P., Hirahara, S., Horányi, A., Muñoz-Sabater, J., Nicolas, J., Peubey, C., Radu, R., Schepers, D., et al. (2020). The era5 global reanalysis. Quarterly Journal of the Royal Meteorological Society, 146(730):1999-2049.

Humphrey, V., Zscheischler, J., Ciais, P., Gudmundsson, L., Sitch, S., and Seneviratne, S. I. (2018). Sensitivity of atmospheric co 2 growth rate to observed changes in terrestrial water storage. Nature, 560(7720):628-631. 
Jones, C. D., Arora, V., Friedlingstein, P., Bopp, L., Brovkin, V., Dunne, J., Graven, H., Hoffman, F., Ilyina, T., John, J. G., et al. (2016). C4mip-the coupled climate-carbon cycle model intercomparison project: Experimental protocol for cmip6. Geoscientific Model Development, $9(8): 2853-2880$.

Jung, M., Reichstein, M., Schwalm, C. R., Huntingford, C., Sitch, S., Ahlström, A., Arneth, A., Camps-Valls, G., Ciais, P., Friedlingstein, P., et al. (2017). Compensatory water effects link yearly global land co 2 sink changes to temperature. Nature, 541(7638):516-520.

Konings, A., Williams, A., and Gentine, P. (2017). Sensitivity of grassland productivity to aridity controlled by stomatal and xylem regulation. Nature Geoscience, 10(4):284-288.

Lenton, T. M., Held, H., Kriegler, E., Hall, J. W., Lucht, W., Rahmstorf, S., and Schellnhuber, H. J. (2008). Tipping elements in the earth's climate system. Proceedings of the national Academy of Sciences, 105(6):1786-1793.

Liu, J., Baskaran, L., Bowman, K., Schimel, D., Bloom, A. A., Parazoo, N. C., Oda, T., Carroll, D., Menemenlis, D., Joiner, J., Commane, R., Daube, B., Gatii, L. V., McKain, K., Miller, J., Stephens, B. B., Sweeney, C., and Wofsy, S. (2020). Carbon monitoring system flux net biosphere exchange 2020 (cms-flux nbe 2020). Earth System Science Data Discussions, 2020:1-53.

Liu, J., Bowman, K. W., Lee, M., Henze, D. K., Bousserez, N., Brix, H., Collatz, G. J., Menemenlis, D., Ott, L., Pawson, S., Jones, D., and Nassar, R. (2014a). Carbon monitoring system flux estimation and attribution: impact of acos-gosat xco2 sampling on the inference of terrestrial biospheric sources and sinks. Tellus B: Chemical and Physical Meteorology, 66(1):22486.

Liu, J., Bowman, K. W., Lee, M., Henze, D. K., Bousserez, N., Brix, H., James Collatz, G., Menemenlis, D., Ott, L., Pawson, S., et al. (2014b). Carbon monitoring system flux estimation and attribution: impact of acos-gosat xco2 sampling on the inference of terrestrial biospheric sources and sinks. Tellus B: Chemical and Physical Meteorology, 66(1):22486. 
Liu, J., Bowman, K. W., Schimel, D. S., Parazoo, N. C., Jiang, Z., Lee, M., Bloom, A. A., Wunch, D., Frankenberg, C., Sun, Y., et al. (2017). Contrasting carbon cycle responses of the tropical continents to the 2015-2016 el niño. Science, 358(6360).

Martens, B., Schumacher, D. L., Wouters, H., Muñoz-Sabater, J., Verhoest, N. E., and Miralles, D. G. (2020). Evaluating the land-surface energy partitioning in era5. Geoscientific Model Development, 13(9):4159-4181.

Nes, E. H. v., Scheffer, M., Brovkin, V., Lenton, T. M., Ye, H., Deyle, E., and Sugihara, G. (2015). Causal feedbacks in climate change. Nature Climate Change, 5(5):nclimate2568.

Novick, K. A., Ficklin, D. L., Stoy, P. C., Williams, C. A., Bohrer, G., Oishi, A. C., Papuga, S. A., Blanken, P. D., Noormets, A., Sulman, B. N., et al. (2016). The increasing importance of atmospheric demand for ecosystem water and carbon fluxes. Nature climate change, 6(11):10231027.

Pan, Y., Birdsey, R. A., Fang, J., Houghton, R., Kauppi, P. E., Kurz, W. A., Phillips, O. L., Shvidenko, A., Lewis, S. L., Canadell, J. G., et al. (2011). A large and persistent carbon sink in the world's forests. Science, 333(6045):988-993.

Piao, S., Wang, X., Wang, K., Li, X., Bastos, A., Canadell, J. G., Ciais, P., Friedlingstein, P., and Sitch, S. (2020). Interannual variation of terrestrial carbon cycle: Issues and perspectives. Global Change Biology, 26(1):300-318.

Popper, K. (2005). The logic of scientific discovery. Routledge.

Stocker, B. D., Zscheischler, J., Keenan, T. F., Prentice, I. C., Seneviratne, S. I., and Peñuelas, J. (2019). Drought impacts on terrestrial primary production underestimated by satellite monitoring. Nature Geoscience, 12(4):264-270.

Sugihara, G., May, R., Ye, H., Hsieh, C.-h., Deyle, E., Fogarty, M., and Munch, S. (2012). Detecting causality in complex ecosystems. science, 338(6106):496-500. 
Sulman, B. N., Roman, D. T., Yi, K., Wang, L., Phillips, R. P., and Novick, K. A. (2016). High atmospheric demand for water can limit forest carbon uptake and transpiration as severely as dry soil. Geophysical Research Letters, 43(18):9686-9695.

Takens, F. (1981). Detecting strange attractors in turbulence. In Dynamical systems and turbulence, Warwick 1980, pages 366-381. Springer.

Tarantola, A. (2006). Popper, bayes and the inverse problem. Nature physics, 2(8):492-494.

Teuling, A. J., Taylor, C. M., Meirink, J. F., Melsen, L. A., Miralles, D. G., Van Heerwaarden, C. C., Vautard, R., Stegehuis, A. I., Nabuurs, G.-J., and de Arellano, J. V.-G. (2017). Observational evidence for cloud cover enhancement over western european forests. Nature communications, 8(1):1-7.

Wang, W., Ciais, P., Nemani, R. R., Canadell, J. G., Piao, S., Sitch, S., White, M. A., Hashimoto, H., Milesi, C., and Myneni, R. B. (2013). Variations in atmospheric co2 growth rates coupled with tropical temperature. Proceedings of the National Academy of Sciences, 110(32):1306113066.

Wang, X., Piao, S., Ciais, P., Friedlingstein, P., Myneni, R. B., Cox, P., Heimann, M., Miller, J., Peng, S., Wang, T., et al. (2014). A two-fold increase of carbon cycle sensitivity to tropical temperature variations. Nature, 506(7487):212-215.

Wenzel, S., Cox, P. M., Eyring, V., and Friedlingstein, P. (2014). Emergent constraints on climatecarbon cycle feedbacks in the cmip5 earth system models. Journal of Geophysical Research: Biogeosciences, 119(5):794-807.

Yuan, W., Zheng, Y., Piao, S., Ciais, P., Lombardozzi, D., Wang, Y., Ryu, Y., Chen, G., Dong, W., Hu, Z., et al. (2019). Increased atmospheric vapor pressure deficit reduces global vegetation growth. Science advances, 5(8):eaax1396. 
Zhou, S., Williams, A. P., Berg, A. M., Cook, B. I., Zhang, Y., Hagemann, S., Lorenz, R., Seneviratne, S. I., and Gentine, P. (2019a). Land-atmosphere feedbacks exacerbate concurrent soil drought and atmospheric aridity. Proceedings of the National Academy of Sciences, 116(38):18848-18853.

Zhou, S., Zhang, Y., Williams, A. P., and Gentine, P. (2019b). Projected increases in intensity, frequency, and terrestrial carbon costs of compound drought and aridity events. Science advances, 5(1):eaau5740.

Zscheischler, J., Westra, S., Van Den Hurk, B. J., Seneviratne, S. I., Ward, P. J., Pitman, A., AghaKouchak, A., Bresch, D. N., Leonard, M., Wahl, T., et al. (2018). Future climate risk from compound events. Nature Climate Change, 8(6):469-477. 


\subsection{Acknowledgment}

A. Barkhordarian is funded by the Deutsche Forschungsgemeinschaft (DFG, German Research Foundation) under Germany's Excellence Strategy - EXC 2037 'CLICCS - Climate, Climatic Change, and Society' - Project Number: 390683824, contribution to the Center for Earth System Research and Sustainability (CEN) of Universität Hamburg. N. Cressie's research was supported by Australian Research Council (ARC) Discovery Project DP190100180. K. Bowman, J. Liu, and J. Jewell acknowledge support from the NASA Interdisciplinary Science Program (NNH16ZDA001N). Part of this work was conducted at the Jet Propulsion Laboratory, California Institute of Technology, under contract with NASA. 


\section{Figures}

a)

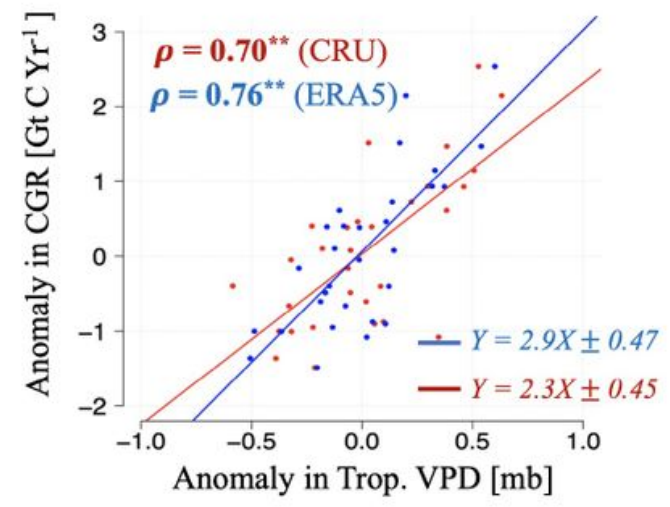

c)

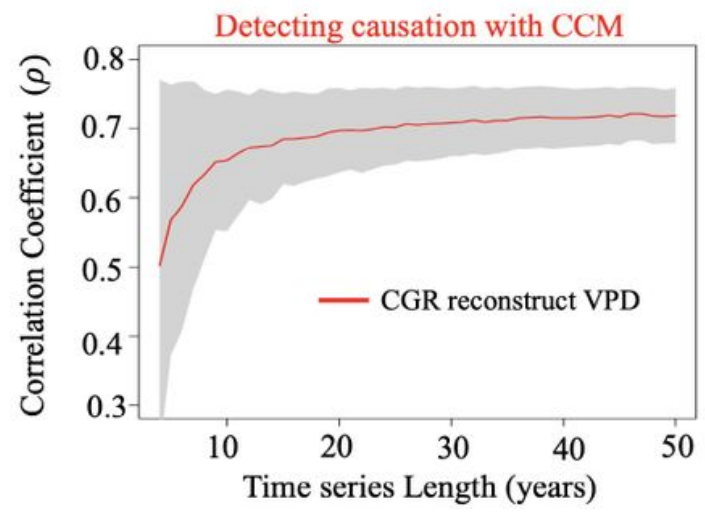

b)

Changes in $\gamma_{V P D}^{C G R}$ over 1960-2018
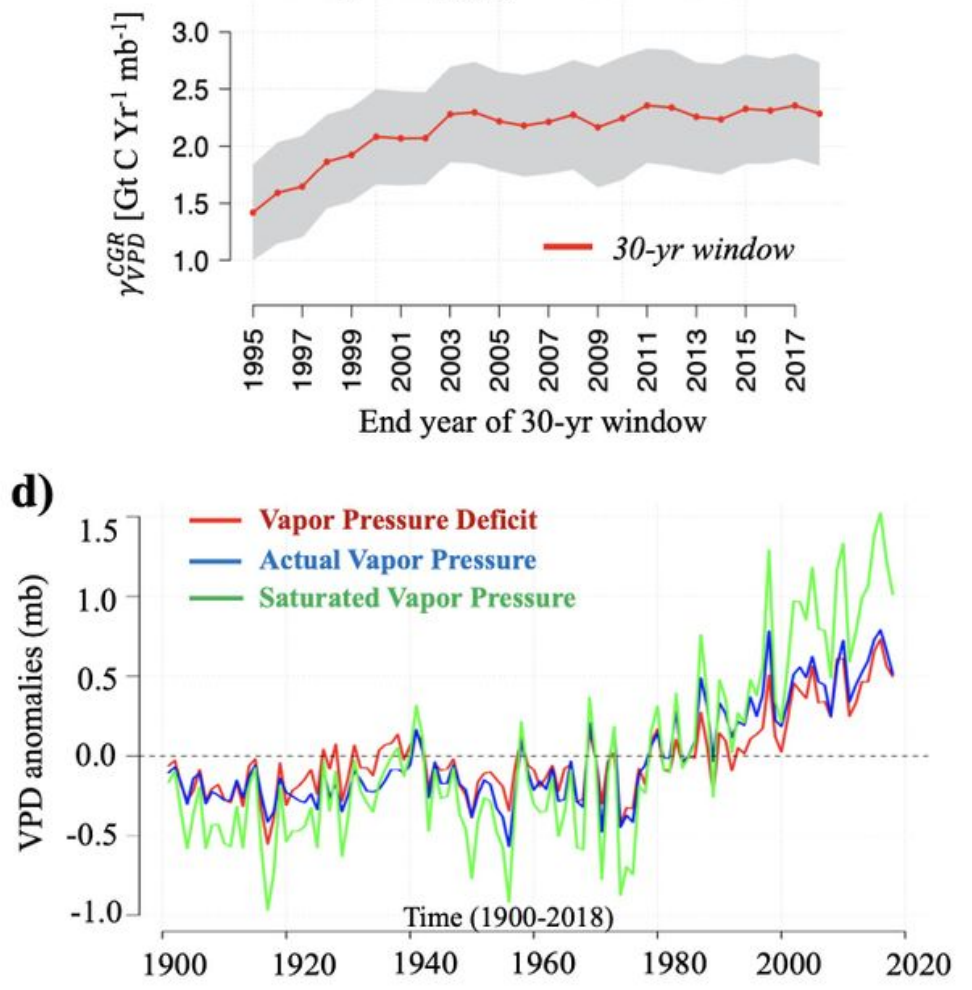

\section{Figure 1}

a) Yearly co-variation between the Global $\mathrm{CO} 2$ growth rate (CGR; converted from ppm to GtC/yr) and Tropical (23N-23S) vapor pressure deficit (VPD) anomalies over the 1989-2018 period, derived from ERA5 and CRUv4 datasets. b) 30-year changes in short-term sensitivity of CGR versus VPD ( CGR V PD) over 1960-2018, units are GtC/yr/mb. Years on the horizontal axis indicate the end year of the 30-yr moving time window used to derive CGR V PD (for example, 2015 represents period 1986\{2015 in the 30-yr time window). The shaded areas show the confidence interval of CGR V PD. c) Convergent cross-mapping for reconstruction of variations in VPD from variations in CGR. Results based on 1000 bootstrapped iterations. Solid line show mean values and shaded area shows 1 standard deviation. d) Time series of observed tropical VPD anomalies (red line) over tropical vegetated area and its components; saturated (green line) and actual (blue line) water vapor pressure; derived from station-based CRUv4 dataset during 1901-2018. Unites are mb. 
a) $N B E=-3.2 * V P D \pm 0.62$

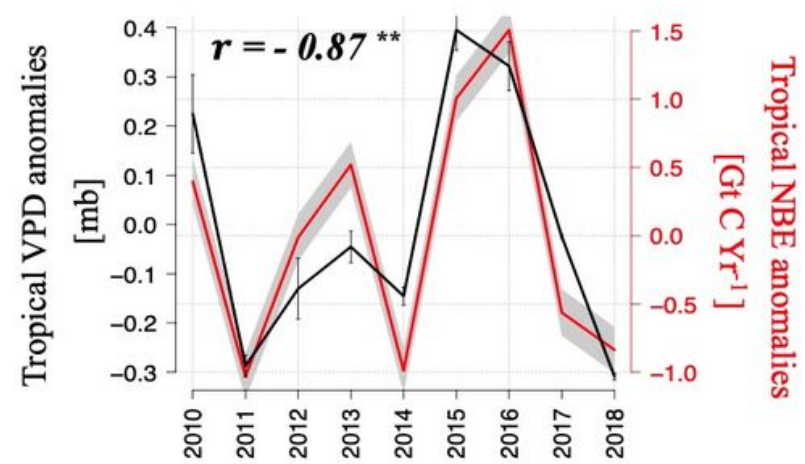

[Note: The vertical axes is inverted for NBE]

d)

Percent variance of VPD explained by Bowen ratio (1981-2018)

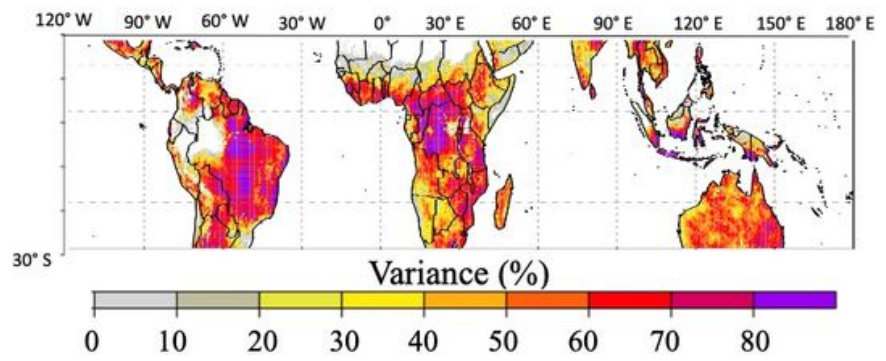

b)

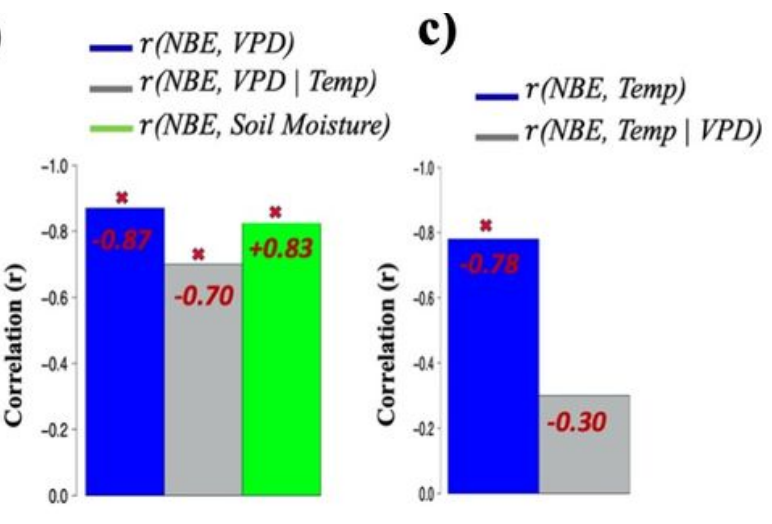

e)

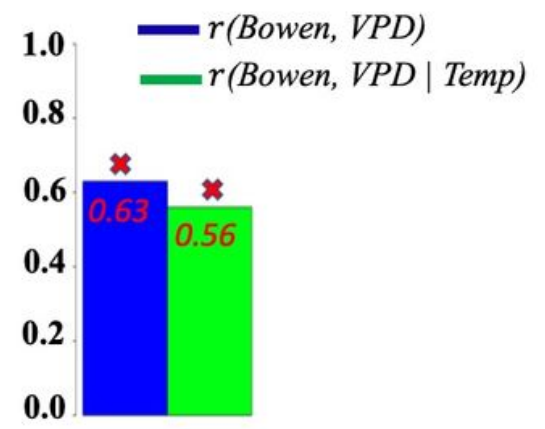

Figure 2

a) Yearly covariation between tropical anomalies of CMS-Flux net biome exchange (NBE) and atmospheric aridity (VPD) over 2010-2018. The whiskers denote the standard deviation among the two observational VPD datasets (CRUv4 and ERA5). The gray shaded area indicates the CMS-Flux NBE uncertainties. b) Correlation ( $r$ ) between NBE and VPD (blue bar), Partial correlation between NBE and VPD after controlling for the effect of temperature (gray bar), correlation between NBE and soil moisture (SM) (green bar, note the positive correlation between NBE and SM). c) Correlation between NBE and 2m temperature (blue bar). Partial correlation between NBE and temperature after controlling for the effect of VPD (gray bar). Significance $(P=0.00)$ is indicated with crosses. $d$ ) The percent variance of VPD variability explained by land-atmospheric interactions (Bowen ratio; proxy for energy partitioning). e) Partial correlation between Bowen ratio and VPD after controlling for the effect of temperature. 
a)

Vapor Pressure Deficit

(CMIP6 models )

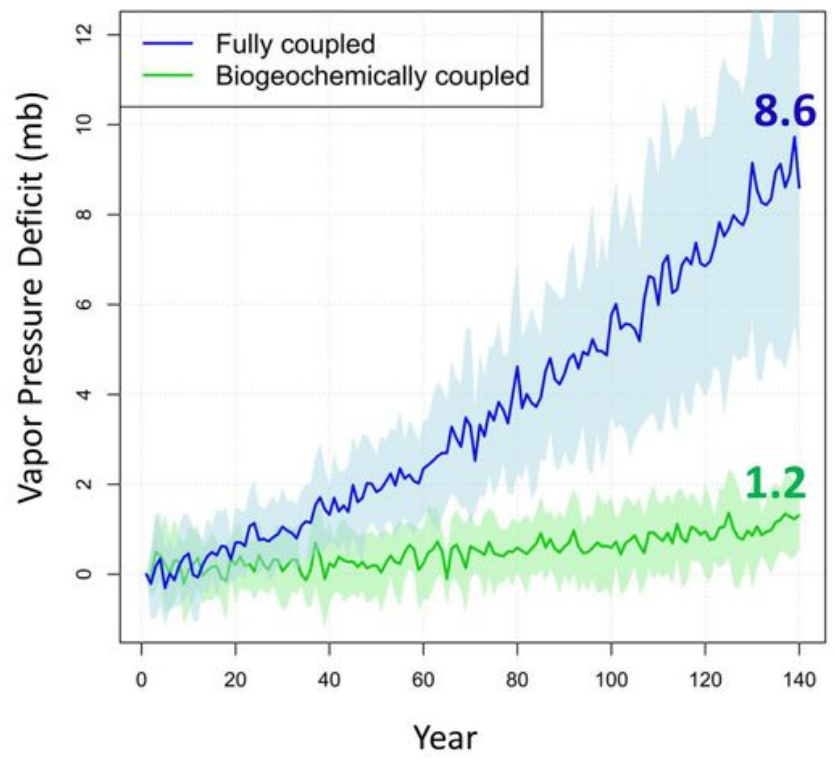

b)

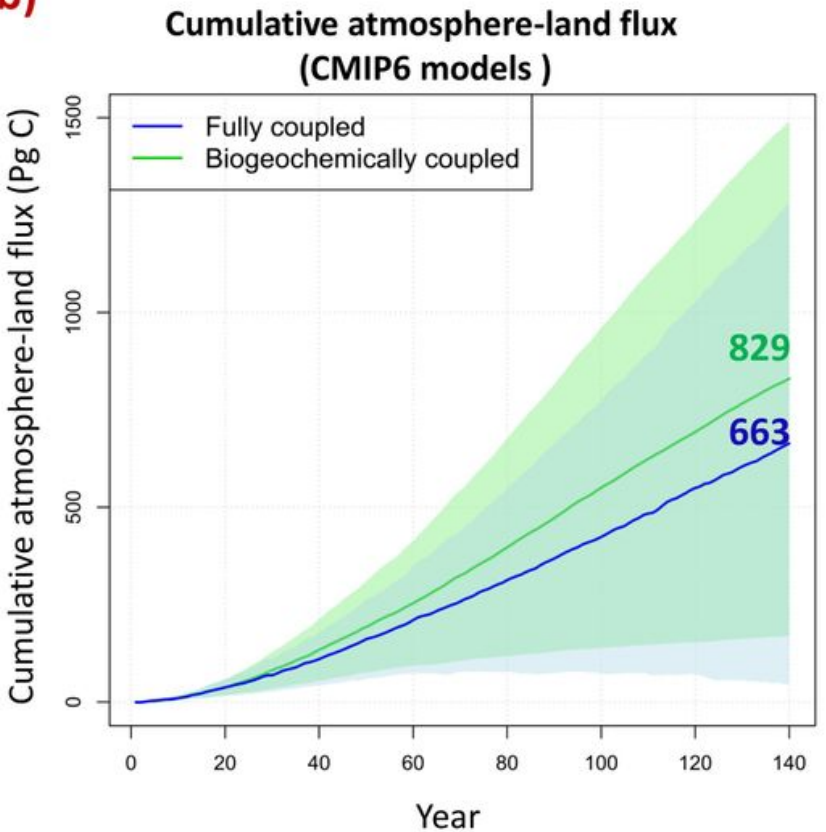

\section{Figure 3}

Quantities used to calculate atmospheric aridity \{carbon cycle feedback parameters ( $T L$ ). a) The projected tropical (23N-23S) mean VPD change in the prescribed $\mathrm{CO} 2$ fully coupled (blue line) and biogeochemically coupled simulations (green line) and the range across 12 ESMs listed in Table 1. (b) Cumulative mean values and the range across 12 ESMs for annual atmosphere $\{$ land $\mathrm{CO} 2$ uxes from the fully (blue line) and biogeochemicaly (green line) coupled simulations of the 1 pctCO2 experiment

a)

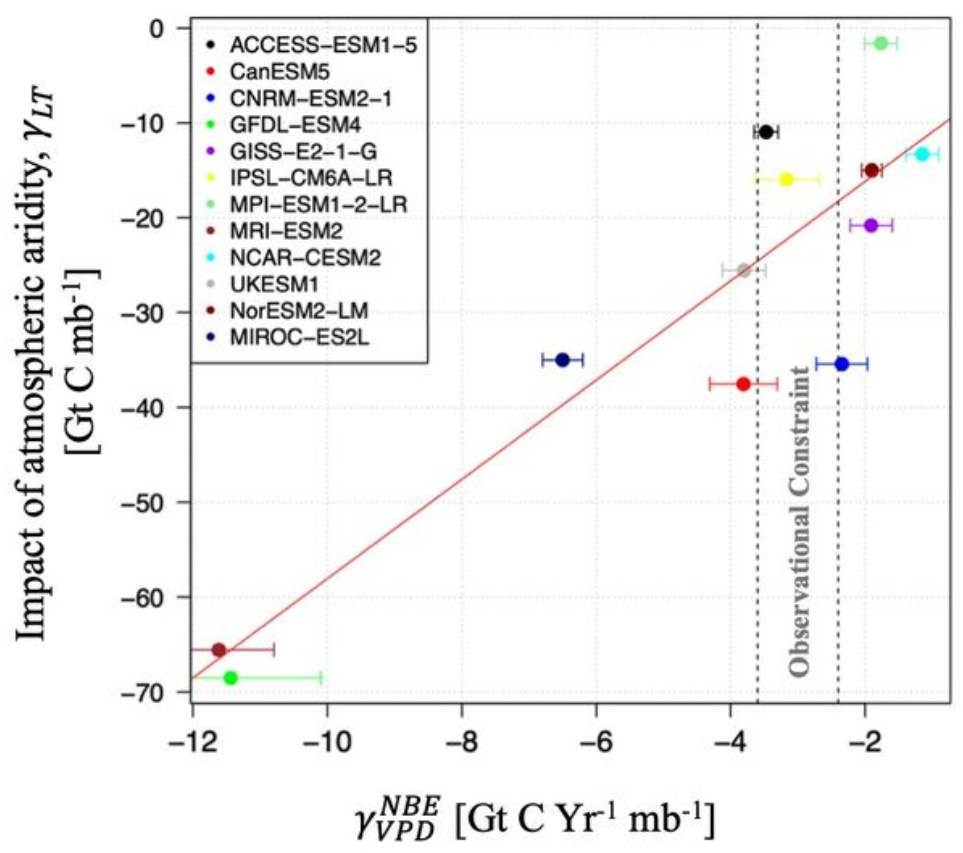

b)

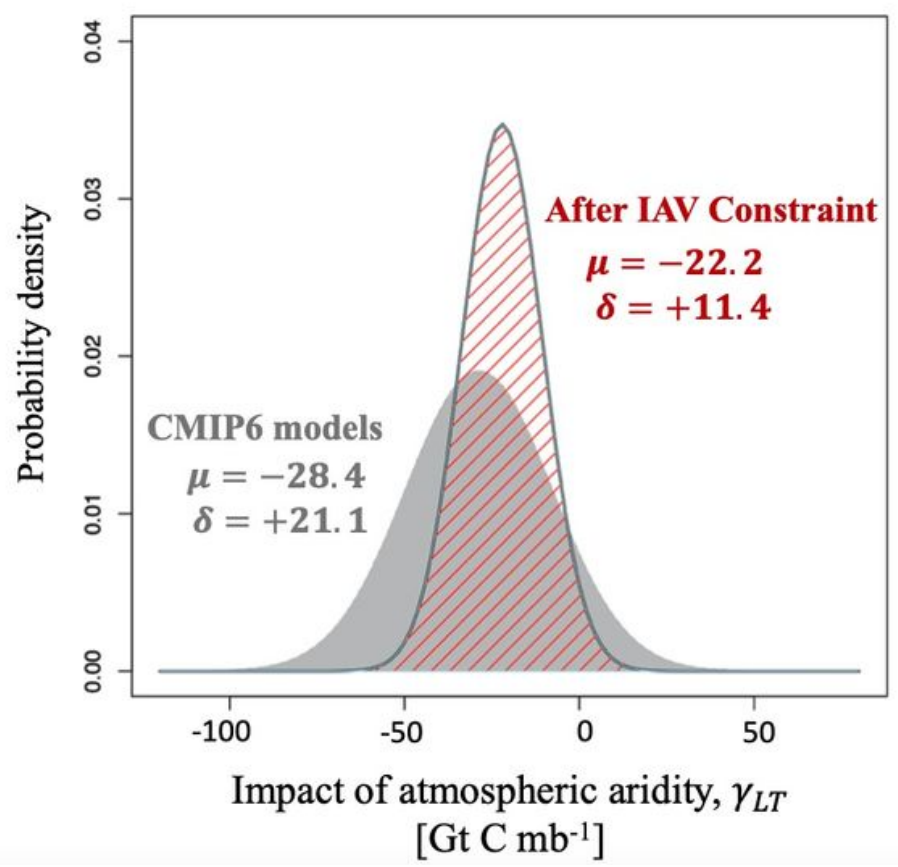


a) The long-term response of tropical land carbon storage to atmospheric aridity ( TL) versus the shortterm sensitivity of tropical NBE to tropical VPD ( NBE V PD) for the 12 ESMs of CMIP6. The correlation between LT and NBE V PD provides an "Emergent Constraint" on the longterm response of land carbon storage to atmospheric aridity. The vertical dashed lines show the range of observed sensitivity. (b) The gray PDF is the prior PDF derived purely from the models before applying the HEC, while the red dashed PDF was derived after applying the HEC on models.

\section{Supplementary Files}

This is a list of supplementary files associated with this preprint. Click to download.

- BarkhordarianSI.pdf 